Article

\title{
Preparation of Porous Activated Carbons for High Performance Supercapacitors from Taixi Anthracite by Multi-Stage Activation
}

\author{
Xiao-Ming Yue ${ }^{1, *}$, Zhao-Yang An ${ }^{1}$, Mei Ye ${ }^{1}$, Zi-Jing Liu ${ }^{1}$, Cui-Cui Xiao ${ }^{1}$, Yong Huang ${ }^{2}$, \\ Yu-Jia Han ${ }^{1}$, Shuang-Quan Zhang ${ }^{1, *}$ and Jun-Sheng $\mathrm{Zhu}^{1}$ \\ 1 Key Laboratory of Coal Processing and Efficient Utilization (Ministry of Education) and School of Chemical \\ Engineering and Technology, China University of Mining and Technology, Xuzhou 221116, China; \\ azy15050837569@163.com (Z.-Y.A.); ye19851623526@163.com (M.Y.); zj18361272159@163.com (Z.-J.L.); \\ 19851625722@163.com (C.-C.X.); 18361227609@163.com (Y.-J.H.); zhujschina@163.com (J.-S.Z.) \\ 2 College of Materials Science and Engineering, Nanjing Forestry University, Nanjing 210037, China; \\ huangyong@njfu.edu.cn \\ * Correspondence: yuexiaoming_cumt@126.com (X.-M.Y.); cumtzsq@126.com (S.-Q.Z.); \\ Tel.: +86-137-7598-7409 (X.-M.Y.); +86-135-1256-7750 (S.-Q.Z.)
}

Received: 9 September 2019; Accepted: 3 October 2019; Published: 5 October 2019

\begin{abstract}
Coal-based porous materials for supercapacitors were successfully prepared using Taixi anthracite (TXA) by multi-stage activation. The characterization and electrochemical tests of activated carbons (ACs) prepared in different stages demonstrated that the $\mathrm{AC}$ from the third-stage activation $\left(\mathrm{AC}_{\mathrm{III}}\right)$ shows good porous structures and excellent electrochemical performances. $\mathrm{AC}_{\mathrm{III}}$ exhibited a fine specific capacitance of $199 \mathrm{~F} \mathrm{~g}^{-1}$ at a current density of $1 \mathrm{~A} \mathrm{~g}^{-1}$ in the three-electrode system, with $6 \mathrm{~mol} \mathrm{~L}^{-1} \mathrm{KOH}$ as the electrolyte. The specific capacitance of $\mathrm{AC}_{\mathrm{III}}$ remained $190 \mathrm{~F} \mathrm{~g}^{-1}$ even despite increasing the current density to $5 \mathrm{~A} \mathrm{~g}^{-1}$, indicating a good rate of electrochemical performance. Moreover, its specific capacitance remained at $98.1 \%$ of the initial value after 5000 galvanostatic charge-discharge (GCD) cycle tests at a current density of $1 \mathrm{~A} \mathrm{~g}^{-1}$, suggesting that the $\mathrm{AC}_{\mathrm{III}}$ has excellent cycle performance as electrode materials for supercapacitors. This study provides a promising approach for fabricating high performance electrode materials from high-rank coals, which could facilitate efficient and clean utilization of high-rank coals.
\end{abstract}

Keywords: supercapacitor; multi-stage activation; coal-based electrodes; activated carbon; electrochemical performance

\section{Introduction}

With the depletion of fossil energy, the storage and conversion of renewable energy has become an urgent problem in the world today [1]. As a kind of high-efficiency energy storage device, supercapacitors have attracted people's attention due to their characteristics of fast charge-discharge rate, high coulombic efficiency, excellent rate performance, and long cycle life [2-5]. Electrode materials are the key factors determining the performance of supercapacitors. At present, they are mainly divided into three categories: carbon materials, transition metal oxides, and conductive polymers [6,7]. Carbon materials mainly include activated carbon (AC) [8,9], carbon fiber [10,11], carbon nanotubes [12,13], carbon nanosheets [14,15], graphene [16-18], etc.

There are abundant coal resources in China, and coal will remain a major source of energy for quite a long time in China. It is very significant and meaningful to research how to use coal efficiently and cleanly, and convert cheap coal into usable materials. As is well-known, coal has become the most commonly used precursor for production of AC because of its abundant resources, low cost, and high 
carbon content [19], and coal-based porous carbon has been widely researched for supercapacitor electrodes. Dong et al. [20] reported interconnected porous carbon nanosheet/nickel foam composites which were obtained from coal tar pitch coupled with $\mathrm{KOH}$ activation. Qin et al. [21] synthesized the interconnected porous carbons from coal tar pitch and microcrystalline cellulose for high-performance supercapacitors. Wang et al. [22] reported a porous carbon with the $1851 \mathrm{~m}^{2} \mathrm{~g}^{-1}$ specific surface area prepared from Xinjiang anthracite through chemical activation with $\mathrm{ZnCl}_{2}$, where the specific capacitance reaches $178 \mathrm{~F} \mathrm{~g}^{-1}$ at $1 \mathrm{~A} \mathrm{~g}^{-1}$. The chemical activators such as $\mathrm{KOH}$ were usually added to coal in solid state to prepare coal-based electrode materials in most papers $[23,24]$. Although this method could produce large surface areas AC, it led to a large amount of activator (activator and coal with mass ratios of 3:1 to 5:1, commonly) and serious corrosion of equipment because the utilization of activator is low, more importantly, the surface areas of the AC has not been effectively utilized through the energy storage process. Therefore, it is necessary to find a low-cost, simple, and environmentally friendly method to produce high-performance supercapacitors. In this work, impregnation method was used to prepare AC with Taixi anthracite (TXA) as a precursor. First, the columnar coal strips were carbonized and physical activated with $\mathrm{CO}_{2}$, then chemically activated after immersion with $\mathrm{KOH}$ solution, next, re-impregnated with $\mathrm{KOH}$ solution, and activated again. $\mathrm{CO}_{2}$ activation can make the material have a certain pore structure, which is beneficial to improving the effect of the impregnation method. It is found that the electrochemical performance of the ACs can be effectively improved by increasing the number of impregnation and activation processes. In addition, it is worth noting that the mass ratio of the activator $(\mathrm{KOH})$ to carbon is only about 1:3 in both chemical activations that followed. The method of impregnation can reduce the $\mathrm{KOH}$ application amount so that the risk of corrosion of equipment can be reduced too, and the remaining $\mathrm{KOH}$ can be recycled.

\section{Results and Discussion}

\subsection{Microstructure and Composition}

The SEM images of TXA and the ACs obtained in each stage are shown in Figure 1. As shown in Figure 1a, TXA has a dense surface and almost no obvious pores, which is attributed to the high degree of coalification of anthracite, which has relatively low porosity. As illustrated in Figure 1b, after the first stage of physical activation, some observable pores appear on the surface of the $A C_{I}$ and there are some irregular fragments on the surface and in the crack of the $A C_{I}$. As Figure 1c shows, after the second stage of chemical activation, more pores (the large pores we can see on the SEM image) appear on the surface of the $\mathrm{AC}_{\mathrm{II}}$ than $\mathrm{AC}_{\mathrm{I}}$. This means the number of macropores of the $\mathrm{AC}_{\mathrm{II}}$ is increased, which can shorten the distance of electrolyte ions diffusing into the micropores in supercapacitor, thereby improving the electrochemical properties of electrode material $[25,26]$. Irregular fragments of $\mathrm{AC}_{\mathrm{II}}$ are reduced due to washing with $\mathrm{HCl}$ solution and deionized water. $\mathrm{AC}_{\mathrm{II}}$ was used as the raw material to repeat the impregnation with the $\mathrm{KOH}$ activator and activation process to obtain $\mathrm{AC}_{\mathrm{III}}$. As illustrated in Figure 1d, compared with the SEM images of TXA, $A C_{I}$, and $A C_{I I}$, the surface of $A C_{I I I}$ is more abundantly porous, and the $\mathrm{AC}_{\mathrm{III}}$ appears to be loose and porous. It is speculated that $\mathrm{AC}_{\mathrm{III}}$ could have a better electrochemical performance as electrode materials. Furthermore, the TEM images of $\mathrm{AC}_{\mathrm{III}}$ (Figure 1e,f) show that its amorphous structure has a large number of pores [21]. 

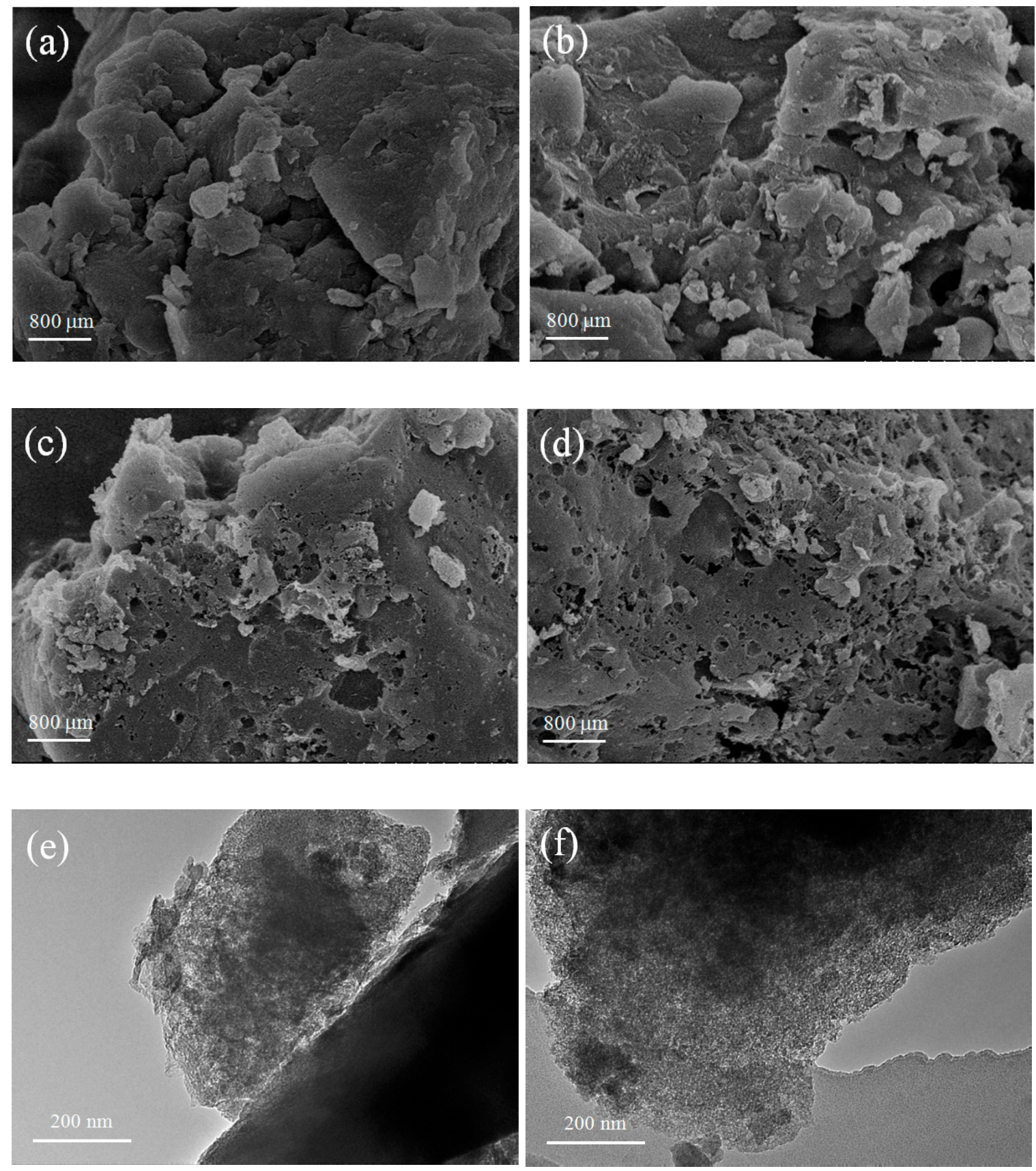

Figure 1. SEM images of Taixi anthracite (TXA) and activated carbons (ACs): (a) TXA; (b) $A C_{I} ;(\mathbf{c}) \mathrm{AC}_{\mathrm{II}}$; (d) $\mathrm{AC}_{\mathrm{III}} ;(\mathbf{e})$ and (f) TEM image of $\mathrm{AC}_{\mathrm{III}}$.

The XRD patterns of TXA, $\mathrm{AC}_{\mathrm{I}}, \mathrm{AC}_{\mathrm{II}}$, and $\mathrm{AC}_{\mathrm{III}}$ are presented in Figure 2. Due to the high degree of coalification, the sharp peak of $26^{\circ}$ and the weak peaks of $43^{\circ}$ are shown in the XRD of TXA, corresponding to the reflection of the (002) plane and (100) plane of the aromatic layer, respectively, indicating the presence of a microcrystalline graphitized structure $[20,27,28]$. Compared with TXA, the peak of $\mathrm{AC}_{\mathrm{I}}$ at $2 \theta=26^{\circ}$ becomes relatively gentle, indicating that the degree of graphitization of $\mathrm{AC}$ decreases after physical activation. In the XRD patterns of $\mathrm{AC}_{\mathrm{II}}$ and $\mathrm{AC}_{\mathrm{III}}$, the (002) peak becomes weaker due to the internal erosion process of $\mathrm{KOH}$ activation [24,29], and the accumulation structure of the aromatic layer further changes to the amorphous structure, resulting in an increase in pores and facilitating the storage of charges. The small peak appeared at $44^{\circ}$ of $\mathrm{AC}_{\mathrm{III}}$ can be indexed to a superposition of the (101) reflections of the graphite structure [30]. This shows that $\mathrm{AC}_{\mathrm{III}}$ after 
three activations has a special structure between the disordered amorphous carbon phase and the graphitic phase.

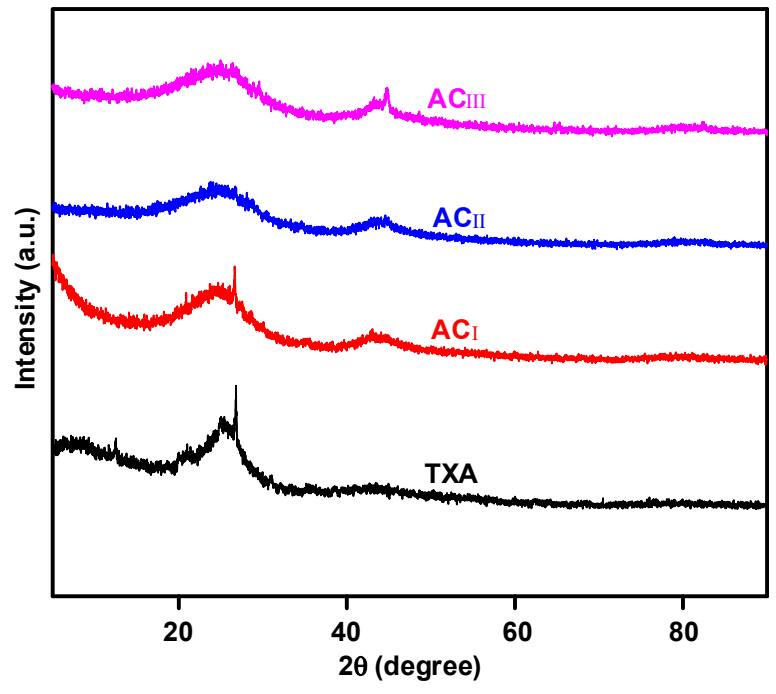

Figure 2. XRD patterns of TXA, $A C_{I}, A_{I I}$ and $A C_{I I I}$.

The electrochemical properties of activated carbon are also affected by the functional groups on the surface. Therefore, FTIR tests were carried out on the samples. As shown in Figure 3, the absorption peaks at 2972 and $2920 \mathrm{~cm}^{-1}$ correspond to the stretching vibration of C-H [31], and the absorption peak at $1380 \mathrm{~cm}^{-1}$ corresponds to the in-plane bending vibration of C-H [32]. The absorption peaks at 845,795 , and $742 \mathrm{~cm}^{-1}$ conform to the out-of-plane bending vibration of $\mathrm{C}-\mathrm{H}$ [33]. Moreover, the peak at about $1640 \mathrm{~cm}^{-1}$ is consistent with the stretching vibration of $C=C$, and the peak at $1610 \mathrm{~cm}^{-1}$ matches with the stretching vibration of the aromatic skeleton, indicating that there is a certain degree of graphitization structure in TXA, which is consistent with the analysis of XRD. It is found that after physical activation, the absorption peaks of ACFS at 1640 and $1610 \mathrm{~cm}^{-1}$ become weak, indicating that the activation process could reduce the graphitization degree of the sample, which is also confirmed in the XRD analysis. In addition, the absorbance for the aromatic skeleton stretching vibration in the FTIR spectrum is further weakening after chemical activation. All samples show a relatively wide band at $3430 \mathrm{~cm}^{-1}$, corresponding to the stretching vibration of hydroxyl [32,34]. TXA has a distinct band at $1040 \mathrm{~cm}^{-1}$, corresponding to the bending vibration of $\mathrm{C}-\mathrm{O}$ [6], which gradually weakens in $\mathrm{AC}_{\mathrm{I}}, \mathrm{AC}_{\mathrm{II}}$, and $\mathrm{AC}_{\mathrm{III}}$, indicating partial cleavage of $\mathrm{C}-\mathrm{O}$ bonds during activation.

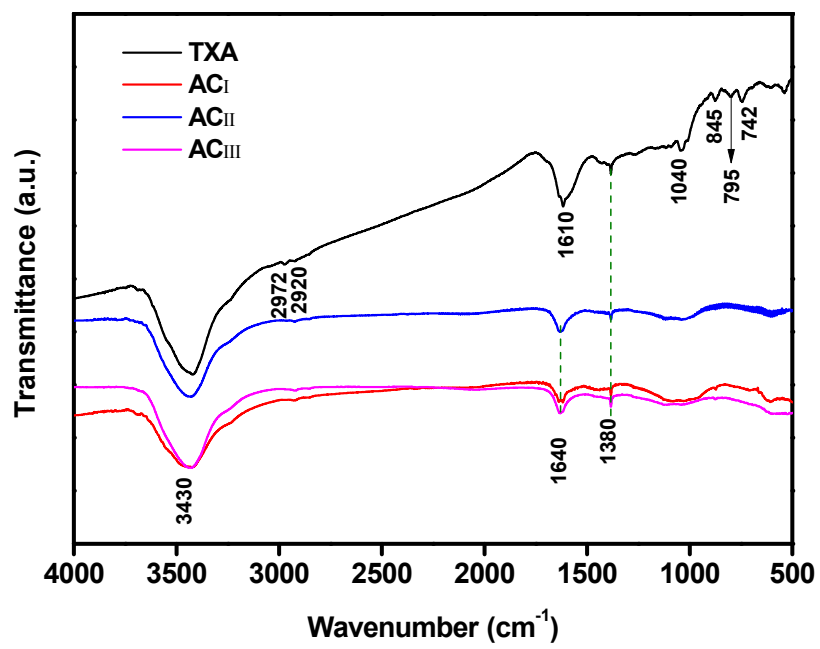

Figure 3. FTIR spectra of TXA, $\mathrm{AC}_{\mathrm{I}}, \mathrm{AC}_{\mathrm{II}}$ and $\mathrm{AC}_{\mathrm{III}}$. 
Two distinct peaks appear in the XPS spectra of TXA and the samples at approximately 285 and $532 \mathrm{Ev}$, corresponding to $\mathrm{C} 1 \mathrm{~s}$ and $\mathrm{O} 1 \mathrm{~s}$, as shown in Figure 4a. The C1s spectra of the samples are separated into four peaks by curve fitting, and are located at the binding energy of 284.8, 285.0, 286.4 , and 288.9 Ev, corresponding to $\mathrm{C}-\mathrm{C}, \mathrm{C}-\mathrm{O}, \mathrm{C}=\mathrm{O}$, and $\mathrm{O}-\mathrm{C}=\mathrm{O}$ functional groups $[26,35]$. This also proves the presence of oxygen-containing functional groups on the surface of the samples. It has been reported that the wettability of the material in aqueous solution is improved due to the presence of oxygen-containing functional groups [36,37], which also contributes to the improvement of the specific capacitance of the electrode.
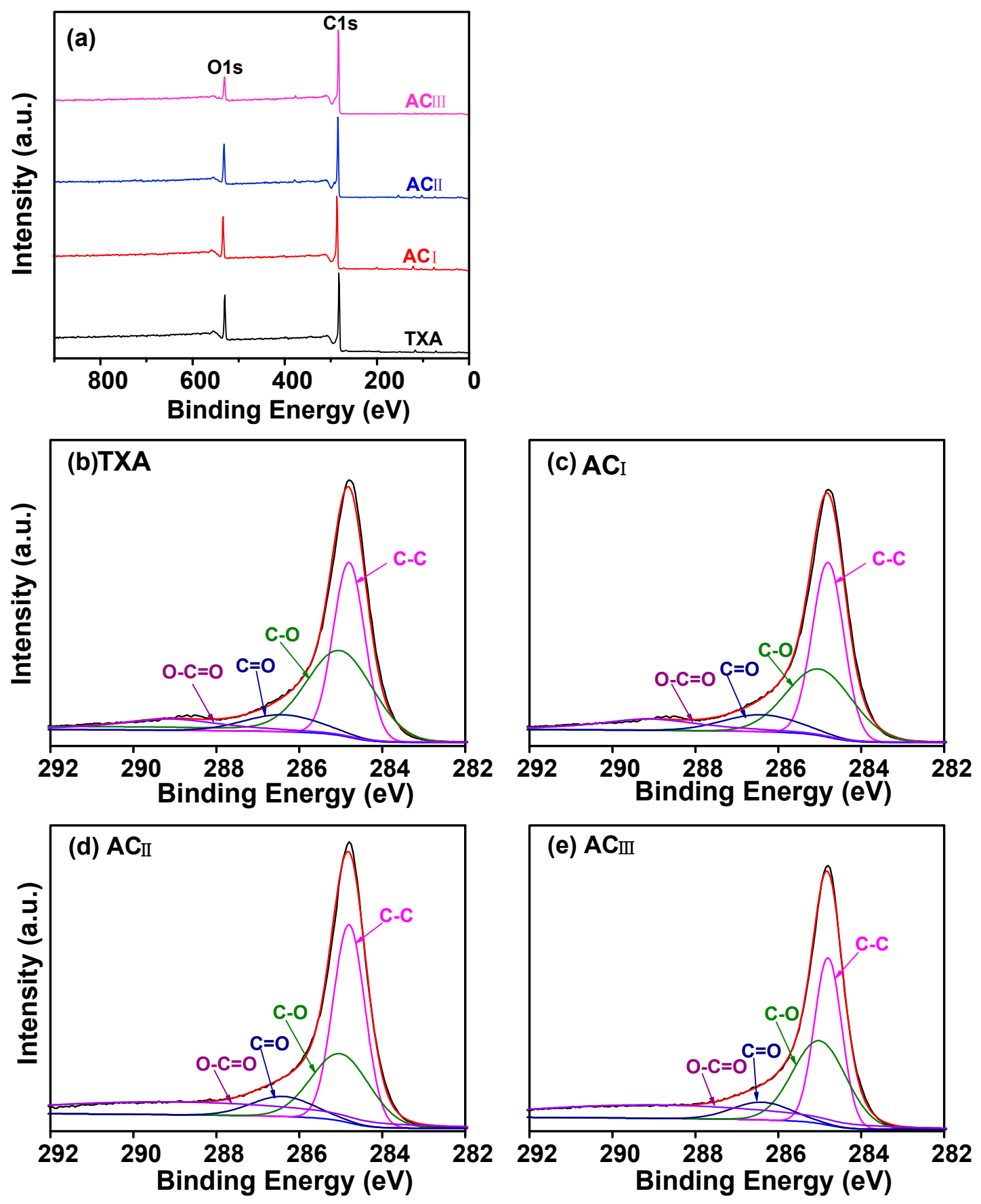

Figure 4. XPS survey spectra of ACs: (a) XPS wide scan spectra; (b-e) High resolution C1s spectra. 
$\mathrm{N}_{2}$ adsorption-desorption analysis of $\mathrm{AC}_{\mathrm{I}}, \mathrm{AC}_{\mathrm{II}}$ and $\mathrm{AC}_{\mathrm{III}}$ was performed, as shown in Figure $5 \mathrm{a}$. According to the classification of International Union of Pure and Applied Chemistry (IUPAC), the $\mathrm{N}_{2}$ adsorption-desorption isotherms of Acs belong to the combination of Type I isotherm and Type IV isotherm, indicating that there are a large number of micropores and a certain number of mesopore in the three samples [26]. The $\mathrm{AC}_{\mathrm{III}}$ shows a large adsorption capacity in the range of low relative pressure and a very obvious $\mathrm{H} 4$ hysteresis loop in the range of 0.4 to 1 relative pressure, proving a large number of mesoporous pores in $\mathrm{AC}_{\mathrm{III}}$ [24]. As illustrated in Figure $5 \mathrm{~b}$, most of the pore diameters of $A C_{I}$ are below $1 \mathrm{~nm}$ and only a few pores diameters of $A C_{I}$ range from 3 to $4 \mathrm{~nm}$. The pore diameters of $\mathrm{AC}_{\mathrm{II}}$ are bigger than $\mathrm{AC}_{\mathrm{I}}$ in the range of $0.5-1 \mathrm{~nm}$, revealing that the $\mathrm{KOH}$ exhibits a remarkable effect of hole-expanding during the first chemical activation. The pores of $\mathrm{AC}_{\mathrm{II}}$ were further developed through the process of impregnation and chemical activation again to produce $\mathrm{AC}_{\mathrm{III}}$, not only the number of the pores with diameters of $0.5-2.5 \mathrm{~nm}$ increased, but also a large number of mesopores appeared at a diameter of 3-4 nm. Chmiola et al. found that the pores with diameters of $0.6-1 \mathrm{~nm}$ can effectively increase the specific capacitance [38]. Specific capacitance can be increased by increasing the number of micropores with suitable pore diameter. In addition, increasing the number of mesopores can effectively increase the ion diffusion channel, reduce the diffusion resistance and improve the utilization of micropores, thereby facilitating the electrochemical performance of the material [39].
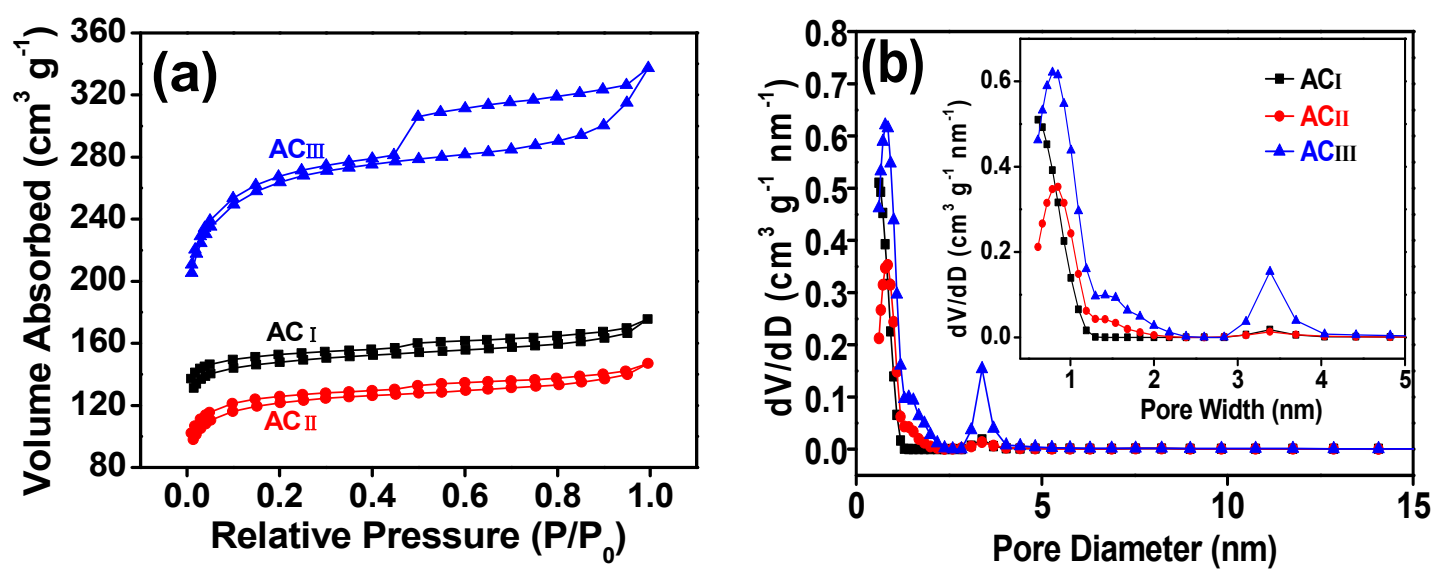

Figure 5. $\mathrm{N}_{2}$ adsorption-desorption isotherms (a) and pore size distribution (b) of $\mathrm{AC}_{\mathrm{I}}, \mathrm{AC}_{\mathrm{II}}$ and $\mathrm{AC}_{\mathrm{III}}$.

The pore structure parameters of the samples are listed in Table 1. Compared with $\mathrm{AC}_{\mathrm{I}}$, the specific surface area $\left(\mathrm{S}_{\mathrm{BET}}\right)$ and micropore volume $\left(\mathrm{V}_{\text {mic }}\right)$ of $A C_{\mathrm{II}}$ are reduced, but the mesopore volume $\left(\mathrm{V}_{\text {mes }}\right)$ and average pore diameter $\left(D_{a p}\right)$ are increased, indicating that the carbon in the inner wall of the micropores reacts with $\mathrm{KOH}$ to enlarge the pore diameter through one-stage activation. The largest contribution to surface area is micropores. In other words, the more micropores of the same quality sample are available, the larger the specific surface area it has. So $\mathrm{AC}_{\mathrm{II}}$ has more mesopores and macropores than $\mathrm{AC}_{\mathrm{I}}$, and a larger average pore diameter than $\mathrm{AC}_{\mathrm{I}}$, but the specific surface area of $\mathrm{AC}_{\mathrm{II}}$ is smaller than $\mathrm{AC}_{\mathrm{I}}$, because $\mathrm{AC}_{\mathrm{I}}$ has more micropores than $\mathrm{AC}_{\mathrm{II}}$. The $\mathrm{S}_{\mathrm{BET}}$, total pore volume $\left(\mathrm{V}_{\mathrm{t}}\right), \mathrm{V}_{\text {mic }}$ and $\mathrm{V}_{\text {mes }}$ of $A C_{\mathrm{III}}$ are obviously increased, proving that the $\mathrm{AC}$ which has undergone impregnation and chemical activation again exhibits more abundant pores, including the enlargement of small pores and generation of new pores. This is consistent with previous SEM analysis.

Table 1. The pore structure parameters of TXA and ACs.

\begin{tabular}{ccccccc}
\hline Samples & $\mathbf{S}_{\text {BET }}\left(\mathbf{m}^{\mathbf{2}} \mathbf{g}^{\mathbf{- 1}}\right)$ & $\mathbf{V}_{\mathbf{t}}\left(\mathbf{c m}^{\mathbf{3}} \mathbf{g}^{\mathbf{- 1}}\right)$ & $\mathbf{V}_{\text {mic }}\left(\mathbf{c m}^{\mathbf{3}} \mathbf{g}^{-\mathbf{1}}\right)$ & $\mathbf{V}_{\text {mes }}\left(\mathbf{c m}^{\mathbf{3}} \mathbf{g}^{-\mathbf{1}}\right)$ & $\mathbf{V}_{\text {mes }} / \mathbf{V}_{\mathbf{t}}(\mathbf{\%})$ & $\mathbf{D}_{\text {ap }}(\mathbf{n m})$ \\
\hline $\mathrm{AC}_{\mathrm{I}}$ & 591.3 & 0.2715 & 0.2263 & 0.0156 & 16.7 & 1.84 \\
$\mathrm{AC}_{\mathrm{II}}$ & 466.1 & 0.2274 & 0.2058 & 0.0216 & 18.7 & 1.95 \\
$\mathrm{AC}_{\mathrm{III}}$ & 984.6 & 0.5219 & 0.3993 & 0.1226 & 23.5 & 2.12 \\
\hline
\end{tabular}


The pore structure of electrode materials has a great influence on electrochemical characteristics. The macropore, like a reservoir, is the place where ions are stored, and the mesopore is the channel for ions to be transported rapidly, moreover, the micropore provides the place for effective charge accumulation. The macropore, mesopore, and micropore are responsible for each other. Therefore, appropriate pore size distribution is conducive to improving the capacitance. As shown in Scheme 1 , the raw coal itself has fewer pores. A large number of pores are formed in $\mathrm{AC}_{\mathrm{I}}$ by one-stage activation, which is mainly microporous, but the few mesopores and macropores that appear in ions cannot move rapidly enough. In the second stage, $\mathrm{KOH}$ is impregnated into the pores of the $\mathrm{AC}_{\mathrm{I}}$, while more pores with larger pore sizes were generated through the reaction of $\mathrm{KOH}$ with the carbon on the pore walls after second-stage activation. Therefore, the mesoporosity of $\mathrm{AC}_{\mathrm{II}}$ increases. In the third stage, more $\mathrm{KOH}$ enter into the pores of $\mathrm{AC}_{\mathrm{II}}$ through impregnation and react with the carbon on the pore walls of $\mathrm{AC}_{\mathrm{II}}$. After that, part of the micropores of $\mathrm{AC}_{\mathrm{II}}$ are reamed to form mesopores, and a large number of new, deeper and more developed micropores are generated around the mesopores. The specific surface area of the activated carbon increased from $591.3 \mathrm{~m}^{2} \mathrm{~g}^{-1}$ to $984.6 \mathrm{~m}^{2} \mathrm{~g}^{-1}$ after being activated twice.

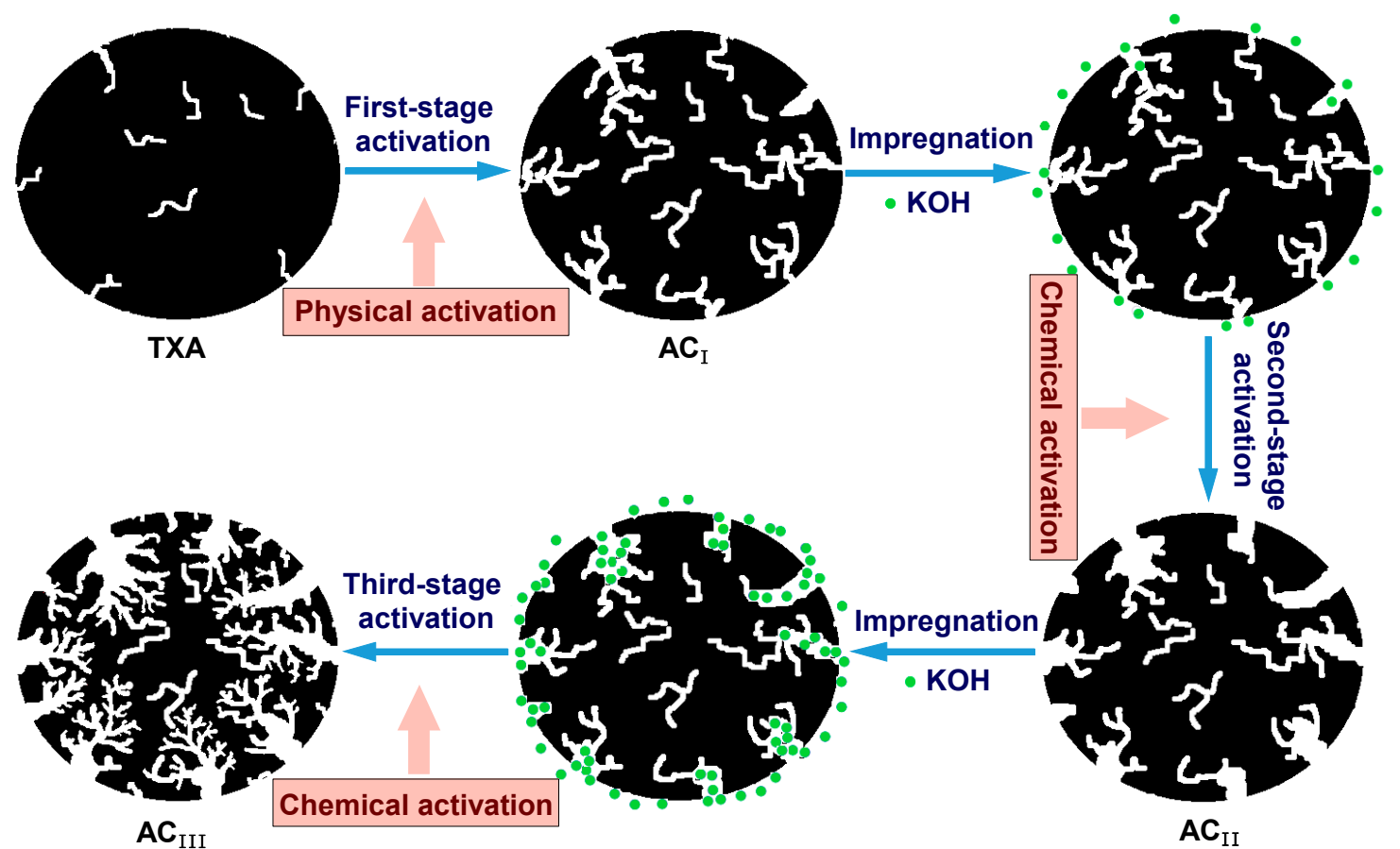

Scheme 1. Schematic of the synthesis strategy of ACs.

The possible pathways for preparation strategy of AC and pore formation were proposed based on the above characterizations, as displayed in Scheme 1. Firstly, TXA was physically activated with $\mathrm{CO}_{2}$ to obtain $\mathrm{AC}_{\mathrm{I}}$, which has a certain amount of micropores and a small amount of mesopores. Secondly, $\mathrm{AC}_{\mathrm{I}}$ was impregnated in $\mathrm{KOH}$ solution, while $\mathrm{K}^{+}$was attaching to the surface of $\mathrm{AC}_{\mathrm{I}}$ and partly entering into the larger diameter pores. Then $\mathrm{AC}_{\mathrm{I}}$ was chemically activated to produce $A C_{\mathrm{II}}$, and the pore size of $\mathrm{AC}_{\mathrm{II}}$ increased obviously due to $\mathrm{K}^{+}$etching. After the impregnation treatment for $\mathrm{AC}_{\mathrm{II}}$, the pore structure was further developed in the subsequent chemical activation process because of the larger pore, leading to transferring more $\mathrm{K}^{+}$into its interior structures. In addition, the use of the impregnation method can make the $\mathrm{K}^{+}$relatively uniform into the pores of the ACs, which may reduce the local excessive etching and the pore collapse due to the uneven distribution of $\mathrm{K}^{+}$. The $\mathrm{AC}_{\mathrm{III}} \mathrm{with}$ more mescopores and high specific surface area was prepared through three-step activation. 


\subsection{Electrochemical Performance}

The electrochemical properties of $\mathrm{AC}_{\mathrm{I}}, \mathrm{AC}_{\mathrm{II}}$, and $\mathrm{AC}_{\mathrm{III}}$ were evaluated by galvanostatic charge-discharge (GCD), cyclic voltammetry (CV), and electrochemical impedance spectroscopy (EIS) tests with a $6 \mathrm{~mol} \mathrm{~L}^{-1} \mathrm{KOH}$ aqueous solution as electrolyte solution in the three-electrode system. The GCD curves of the three samples at $1 \mathrm{~A} \mathrm{~g}^{-1}$ current density, as taken in Figure 6a, show that all curves are highly symmetric triangles, indicating that the electrode materials have typical double layer capacitor characteristics and good electrochemical reversibility [40,41]. Clearly, $\mathrm{AC}_{\mathrm{III}}$ shows the longest discharge time, indicating that it has the largest specific capacitance among the three samples under the same test conditions [42,43]. Besides, according to the Equation (1), the specific capacitances of $A C_{I}$, $\mathrm{AC}_{\mathrm{II}}$, and $\mathrm{AC}_{\mathrm{III}}$ at $1 \mathrm{~A} \mathrm{~g}^{-1}$ are 81,106 , and $199 \mathrm{~F} \mathrm{~g}^{-1}$, respectively. Compared with $\mathrm{AC}_{\mathrm{I}}$ and $\mathrm{AC}_{\mathrm{II}}, \mathrm{AC}_{\mathrm{III}}$ has a significant increase in specific capacitance, which is 2.45 times that of ACSF and 1.88 times that of $\mathrm{AC}_{\mathrm{II}}$, proving the importance of re-impregnation and activation of activated carbon. In addition, the voltage drop of the three activated carbon samples at a current density of $1 \mathrm{~A} \mathrm{~g}^{-1}$ are shown in Figure $6 \mathrm{~b}$. The voltage drops of $\mathrm{AC}_{\mathrm{I}}, \mathrm{AC}_{\mathrm{II}}$, and $\mathrm{AC}_{\mathrm{III}}$ are $0.0312,0.0275$, and $0.0148 \mathrm{~V}$, respectively, and the values decrease in turn, indicating that the internal resistance of the electrode is reduced [21]. This may be related to the fact that multiple activation increases the pore size and reduces the diffusion resistance. Magnification performance is one of the key factors affecting the practical application of electrode materials. The specific capacitances of $\mathrm{AC}_{\mathrm{I}}, \mathrm{AC}_{\mathrm{II}}$, and $\mathrm{AC}_{\mathrm{III}}$ at different current densities are shown in Figure $6 \mathrm{c}$. It is clear that at the same current density, the specific capacitance of $\mathrm{AC}_{\mathrm{III}}$ is much higher than $\mathrm{AC}_{\mathrm{I}}$ and $\mathrm{AC}_{\mathrm{II}}$, reaching $206 \mathrm{~F} \mathrm{~g}^{-1}$ at $0.5 \mathrm{~A} \mathrm{~g}^{-1}$. Even if the current density reaches $5 \mathrm{~A} \mathrm{~g}^{-1}$, the specific capacitance of $\mathrm{AC}_{\mathrm{III}}$ is still $190 \mathrm{~F} \mathrm{~g}^{-1}$, showing excellent rate performance. This is due to the more reasonable pore size distribution of $\mathrm{AC}_{\mathrm{III}}$, especially the increase of mesopores, which is conducive to the rapid transmission of electrolyte ions.

Figure $6 \mathrm{~d}$ shows the $\mathrm{CV}$ curves for all samples at a scan rate of $10 \mathrm{mV} \mathrm{s}^{-1}$. All curves exhibit an approximately rectangular character, exhibiting excellent capacitive behavior, which illustrates that the capacitance of all samples is primarily derived from the electrical double-layer capacitance behavior [44-46]. Moreover, it is observed that the CV curve has a certain degree of distortion, which is due to the pseudo capacitance effect provided by the fast redox reaction of oxygen-containing functional groups [47]. It is well known that the integral area of the CV curve corresponds to the capacitance of the supercapacitor. Therefore, $\mathrm{AC}_{\mathrm{III}}$ has the largest specific capacitance at the same scanning rate. Besides, the $\mathrm{CV}$ curve of $\mathrm{AC}_{\mathrm{III}}$ at a scan rate of 5 to $100 \mathrm{mV} \mathrm{s}^{-1}$ is exhibited in Figure 6e. Even at relatively high scan rates, the $\mathrm{CV}$ curve of $\mathrm{AC}_{\mathrm{III}}$ remains approximately rectangular, exhibiting good electrochemical behavior, due to the presence of a large number of mesopores facilitating the rapid transmission of electrolyte ions within the pores, which is in accordance with the analysis of GCD.

In order to make further evaluation of the ACs performance as electrode materials of supercapacitors, EIS analysis are performed. Figure $6 \mathrm{f}$ is the Nyquist plots of the samples, in which the illustration is an enlarged view of the high frequency region. Clearly, all curves show a diagonal line in the low frequency region and a semicircle in the high frequency region. In general, the slope of the linear portion of the Nyquist diagram in the low frequency region is related to the diffusion resistance caused by the diffusion/transmission of the electrolyte ions in the electrolyte and the electrode material, and the larger the slope, the closer the supercapacitor is to the ideal capacitor behavior [48-50]. Then the slope of $\mathrm{AC}_{\mathrm{III}}$ is obviously greater than that of $\mathrm{AC}_{\mathrm{I}}$ and $\mathrm{AC}_{\mathrm{II}}$, indicating that $\mathrm{AC}_{\mathrm{III}}$ has smaller diffusion resistance, which is consistent with the analysis of $\mathrm{N}_{2}$ adsorption and desorption test. The diameter of the semicircle in the high frequency region corresponds to the charge transfer resistance $\left(R_{c t}\right)[51,52]$. It is clear that the $\mathrm{R}_{\mathrm{ct}}$ of $\mathrm{AC}_{\mathrm{I}}, \mathrm{AC}_{\mathrm{II}}$, and $\mathrm{AC}_{\mathrm{III}}$ in the illustration in Figure $6 \mathrm{f}$ increases sequentially, due to the decrease in the degree of graphitization of AC during the activation process, which is in accord with the $\mathrm{XRD}$ analysis. In addition, the solution resistance $\left(R_{S}\right)$ can be obtained from the $Z^{\prime}$ axis intercept of the Nyquist plot [4], and the $R_{S}$ values of all samples are very small, which also reflects the excellent electrochemical performance of the prepared materials. The cyclic stability is also an important index for evaluating the performance of supercapacitors. Therefore, the 5000 GCD cycle tests were executed 
for $\mathrm{AC}_{\mathrm{III}}$ at $1 \mathrm{~A} \mathrm{~g}^{-1}$, as shown in Figure 7 . It is worth noting that in the first 200 cycles, the specific capacitance of $\mathrm{AC}_{\mathrm{III}}$ increases significantly, indicating that the $\mathrm{AC}$ electrodes undergo electrochemical activation in the incipient charge and discharge processes. And during electrochemical activation, the suitable charge-discharge cycles can promote the electrolyte ions to be completely inserted into the pores of $\mathrm{AC}$, thus improving the availability of the surface area of the charge storage [53]. More impressively, the specific capacitance of the $\mathrm{AC}_{\mathrm{III}}$ remained at $98.1 \%$ of the initial value after 5000 cycles, showing excellent cycle performance. Based on the above analysis, $\mathrm{AC}_{\mathrm{III}}$ exhibits relatively high specific capacitance, excellent rate performance, and reliable cycle stability, which is more in line with practical application requirements.
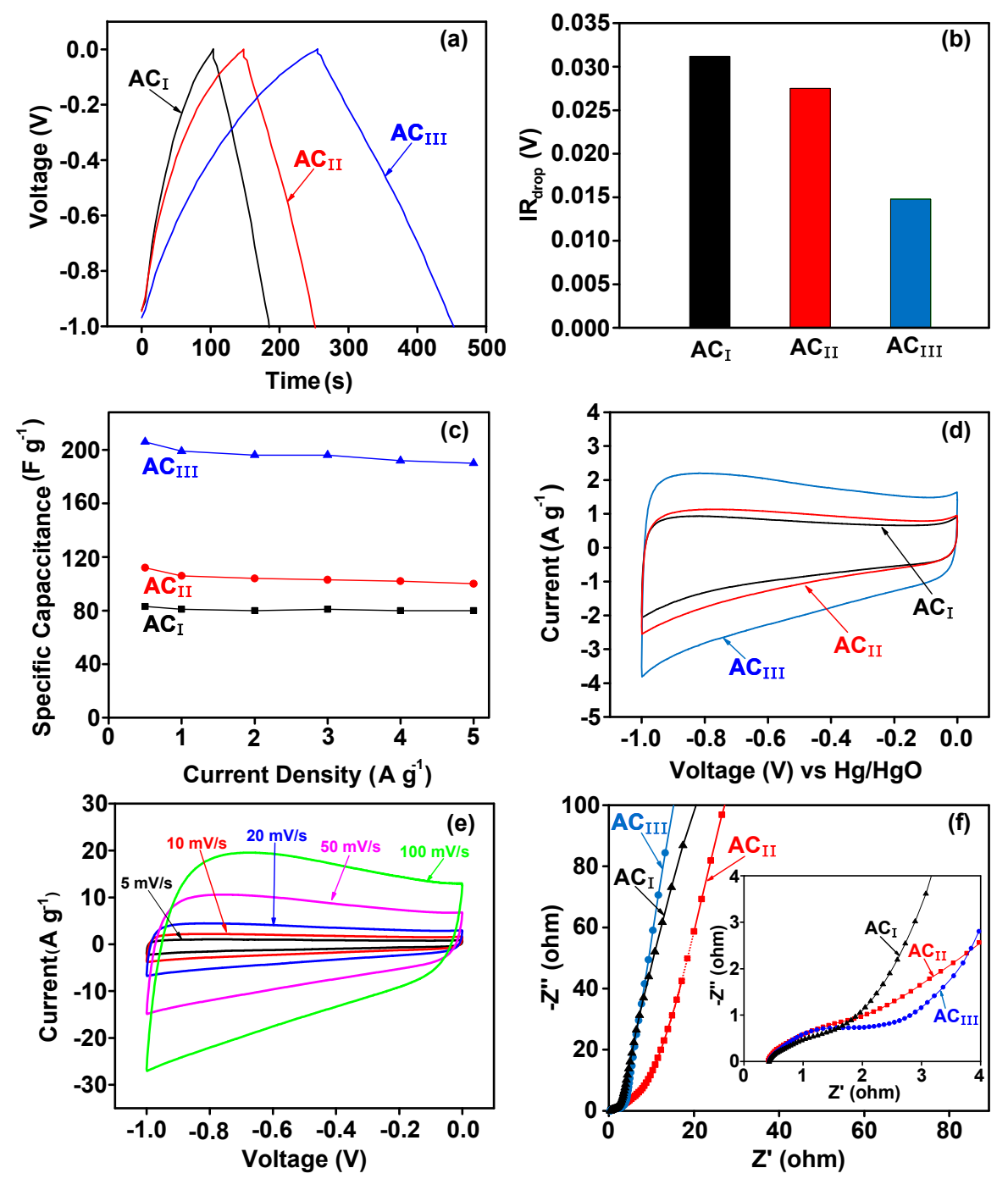

Figure 6. (a) Galvanostatic charge-discharge (GCD) curves of AC electrodes in $6 \mathrm{M} \mathrm{KOH}$ electrolyte at $1 \mathrm{~A} \mathrm{~g}^{-1}$; (b) The voltage drops of AC electrodes at $1 \mathrm{~A} \mathrm{~g}^{-1}$; (c) Specific capacitance of AC electrodes at different current densities; (d) CV curves of AC electrodes at $10 \mathrm{mV} \mathrm{s}^{-1}$; (e) CV curves of $\mathrm{AC}_{\text {III }}$ electrodes at different scan rates; (f) Nyquist plots of AC electrodes. 


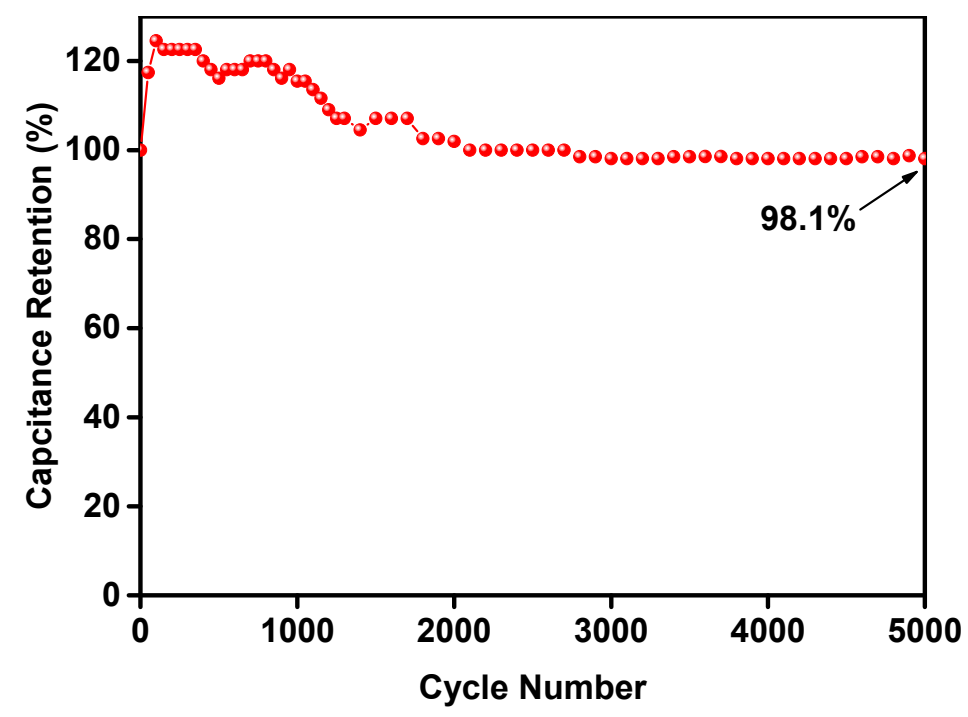

Figure 7. Cycle stability of $\mathrm{AC}_{\mathrm{III}}$ electrodes measured at $1 \mathrm{~A} \mathrm{~g}^{-1}$.

\section{Materials and Methods}

\subsection{Materials}

Anthracite collected from Taixi, Ningxia province was taken as the precursor of ACs. Its proximate and ultimate analyses are shown in Table 2. Coal tar as the binder of columnar ACs was purchased from Jiangsu Weitian Chemical Group Company. $\mathrm{KOH}$ and hydrochloric acid used in the experiment were purchased from Sinopharm Chemical Reagent Co., Ltd. Acetylene black, anhydrous ethanol and potassium nitrate were purchased from Xiqiao Chemical Co., Ltd. All chemical reagents were of analytical grade and used directly without further purification.

Table 2. Proximate and ultimate analyses of Taixi anthracite.

\begin{tabular}{ccccccccc}
\hline \multicolumn{3}{c}{ Proximate Analysis (wt. $\%$ ) } & \multicolumn{4}{c}{ Ultimate Analyses (wt. $\%$, daf) } \\
\hline $\boldsymbol{M}_{\mathbf{a d}}$ & $\boldsymbol{A}_{\mathbf{d}}$ & $\boldsymbol{V M}_{\mathbf{d a f}}$ & $\boldsymbol{F C}_{\mathbf{d a f}^{\mathbf{a}}}$ & $\mathbf{C}$ & $\mathbf{H}$ & $\mathrm{O}^{\mathrm{a}}$ & $\mathrm{N}$ & $\mathrm{S}$ \\
\hline 1.45 & 3.88 & 7.67 & 92.33 & 94.67 & 2.49 & 1.90 & 0.75 & 0.19 \\
\hline \multicolumn{4}{c}{ ad: air dry basis; d: dry basis; daf: dry and ash-free basis. ${ }^{\text {a }}$ By difference. }
\end{tabular}

\subsection{Preparation of $A C$}

\subsubsection{Pretreatment of TXA}

TXA was crushed and ground to below 200 mesh. Then $100 \mathrm{~g}$ TXA thoroughly stirred by adding $2 \mathrm{~g} \mathrm{KNO}_{3}, 32.5 \mathrm{~g}$ coal tar and $5 \mathrm{ml}$ deionized water. After that, it was pressed into cylindrical strips having a diameter of $2.8 \mathrm{~mm}$ by a plodder. Finally, the strips were naturally dried and broken until they were $1-2 \mathrm{~cm}$ long.

\subsubsection{The First-Stage Activation by Physical Activation}

The treated strip was put into muffle furnace at room temperature and heated at $12{ }^{\circ} \mathrm{C} \mathrm{min}^{-1}$ to $600{ }^{\circ} \mathrm{C}$ under nitrogen flow for carbonization. After carbonization, the sample was activated with $\mathrm{CO}_{2}$ as activator in a horizontal tube furnace with a heating rate of $12{ }^{\circ} \mathrm{C} \mathrm{min}-1$ from room temperature to $900{ }^{\circ} \mathrm{C}$, and kept at $900^{\circ} \mathrm{C}$ for $2 \mathrm{~h}$. The sample was cooled to room temperature and then washed several times with $1 \mathrm{~mol} \mathrm{~L}^{-1} \mathrm{HCl}$ solution, followed by washing with deionized water until the solution was neutral. Afterwards, the sample was dried at $80^{\circ} \mathrm{C}$ for $24 \mathrm{~h}$ and denoted as the first-stage activated carbon $\left(\mathrm{AC}_{\mathrm{I}}\right)$. 


\subsubsection{The Second-Stage Activation by Chemical Activation}

$\mathrm{AC}_{\mathrm{I}}$ was impregnated in $12 \mathrm{~mol} \mathrm{~L}^{-1} \mathrm{KOH}$ solution and magnetically stirred for $24 \mathrm{~h}$ at room temperature. The sample was then filtered and dried at $80^{\circ} \mathrm{C}$ for $24 \mathrm{~h}$. In addition, the sample was weighed before and after immersion, and the corresponding mass ratio of alkali to carbon was about 1:3 by difference method. After that, the sample was placed in a tube furnace with $\mathrm{N}_{2}$ as a shielding gas and heated from room temperature to $800{ }^{\circ} \mathrm{C}$ at $12{ }^{\circ} \mathrm{C} \mathrm{min}{ }^{-1}$ for $1 \mathrm{~h}$. Then the activated sample was cooled to room temperature and washed several times with $1 \mathrm{~mol} \mathrm{~L}^{-1} \mathrm{HCl}$ solution, followed by washing with deionized water until the solution was neutral. The resulting columnar $\mathrm{AC}$ was then dried at $80^{\circ} \mathrm{C}$ for $24 \mathrm{~h}$ and denoted as activated carbon from the second-stage activation $\left(\mathrm{AC}_{\mathrm{II}}\right)$.

\subsubsection{The Third-Stage Activation by Chemical Activation}

The procedure described in 2.2.3 for $\mathrm{AC}_{\mathrm{II}}$ was repeated and the resulting $\mathrm{AC}$ was recorded as activated carbon for the third stage $\left(\mathrm{AC}_{\mathrm{III}}\right)$.

\subsection{Characterizations}

The microstructure of ACs was analyzed by scanning electron microscopy (SEM, Hitachi, Su8020) with a field emission scanning electron microanalyzer at $5 \mathrm{kV}$. Transmission electron microscope measurements were carried out on a microscope (TEM, FEI, Tecnai G2 F20) at $200 \mathrm{kV}$. X-ray diffraction (XRD) analysis was performed at $40 \mathrm{kV}$ and $30 \mathrm{~mA}$ using a Bruker D8 Advance diffractometer with a $\mathrm{Cu} \mathrm{Ka} \mathrm{X-ray} \mathrm{source,} \mathrm{the} \mathrm{scan} \mathrm{range} \mathrm{was} \mathrm{between} 5$ and $90^{\circ}$. Fourier transform infrared (FTIR) spectra of the samples were obtained by a Nicolet is 5 infrared spectrometer by using pressed $\mathrm{KBr}$ pellets. X-ray photoelectron spectroscopy (XPS) was implemented on an ESCALAB 250Xi (Thermo Fisher) instrument with monochromatized $\mathrm{Al} \mathrm{K} \alpha$ probe beam. The energy scale was corrected with $\mathrm{C} 1 \mathrm{~s}$ peak at $284.8 \mathrm{eV}$ as internal standard. The transmit power is $250 \mathrm{~W}$ and it was used for wide-range scanners and narrow scans over the ranges of 0-900 eV and 282-292 eV respectively, at a pass energy of $100 \mathrm{eV}$ and $20 \mathrm{eV}$, respectively. The background was subtracted use a function of Shirley. The $\mathrm{N}_{2}$ adsorption-desorption isotherm was measured at $77 \mathrm{~K}$ using an Autosorb- 1 type adsorbent manufactured by Quantachrome, and the specific surface areas $\left(\mathrm{S}_{\mathrm{BET}}\right)$ were calculated by the Brunauer-Emmett-Teller (BET) equation. The total pore volume $\left(\mathrm{V}_{\mathrm{t}}\right)$ of the sample was calculated from the relative pressure $\left(\mathrm{P} / \mathrm{P}_{0}\right)$ of 0.99 . The pore size distribution was calculated by density functional theory (DFT). The average pore diameter $\left(D_{a p}\right)$ of the sample was calculated from Equation (1).

$$
D_{a p}=\frac{4 V_{t}}{S_{B E T}}
$$

\subsection{Electrochemical Measurement}

Briefly, the AC we prepared was pulverized to pass through a 200-mesh sieve. $20 \mathrm{mg}$ AC powder, $2.5 \mathrm{mg}$ acetylene black, and $2.5 \mathrm{mg}$ polytetrafluoroethylene were mixed into ethanol, followed by ultrasonic treatment for $5 \mathrm{~min}$. Then the mixture was uniformly applied to long strips of foamed nickel, and dried in vacuum at $80^{\circ} \mathrm{C}$ for $24 \mathrm{~h}$. The active mass of the electrode was ca. $2 \mathrm{mg} \mathrm{cm}^{-2}$. All samples were electrochemically tested in a $6 \mathrm{~mol} / \mathrm{L} \mathrm{KOH}$ solution with nickel foam coated with ACs as working electrode, platinum sheet as the counter electrode, and $\mathrm{Hg} / \mathrm{HgO}$ electrode as the reference electrode.

The GCD tests were performed at room temperature using a NEWARE BTS high precision battery detection system at a current density of $0.5-5 \mathrm{~A} \mathrm{~g}^{-1}$. Cyclic voltammetry (CV) tests were measured using a CHI66D electrochemical workstation ( $\mathrm{CH}$ Instrument, Shanghai, China) at a voltage range of -1 to $0 \mathrm{~V}$. Electrochemical impedance spectroscopy (EIS) measurements were conducted at an open circuit potential with an AC amplitude of $10 \mathrm{mV}$ over a frequency range of $1 \mathrm{mHz}$ to $100 \mathrm{kHz}$. The specific capacitance under three-electrode system was calculated according to Equation (2): 


$$
C=\frac{I \Delta t}{m \Delta V}
$$

where I (A) is the discharge current; $m(\mathrm{~g})$ is the mass of the AC; $\Delta t(\mathrm{~s})$ is the discharge time interval; $\Delta V(\mathrm{~V})$ is the voltage difference during the corresponding discharge time.

\section{Conclusions}

In conclusion, a lot of micropores in $\mathrm{AC}_{\mathrm{I}}$ were generated through carbonization and physical activation with $\mathrm{CO}_{2}$ as an activator. The volumes of micropores and mesopores in $\mathrm{AC}_{\mathrm{III}}$ were increased significantly more than that in $\mathrm{AC}_{\mathrm{I}}$ after two impregnations of $\mathrm{KOH}$ solution and two activations at $800^{\circ} \mathrm{C}$ for $1 \mathrm{~h}$. When using the ACs as active substances in the three-electrode system, the specific capacitance of $\mathrm{AC}_{\mathrm{III}}$ was $206 \mathrm{~F} \mathrm{~g}^{-1}$ at $0.5 \mathrm{~A} \mathrm{~g}^{-1}$, much higher than $\mathrm{AC}_{\mathrm{I}}$ and $\mathrm{AC}_{\mathrm{II}}$. It shows higher specific capacitance, excellent rate performance, and good cycling stability of $\mathrm{AC}_{\mathrm{III}}$. In addition, the impregnation method can reduce the dosage of $\mathrm{KOH}$ and reduce the corrosion of equipment during the activation process. The method adopted in this paper may pave the way for industrial production of carbon-based electrode materials for high high-performance supercapacitors.

Author Contributions: X.-M.Y. and S.-Q.Z. designed the experiment, supervised the work and revised the manuscript; Z.-Y.A. and Y.-J.H. performed the experiments; Z.-Y.A. wrote the paper; M.Y., C.-C.X. and Z.-J.L. carried out for characterization; Y.H. and J.-S.Z. contributed to commented the manuscript. All authors have read and approved the manuscript.

Funding: This work was supported by the National Key Research and Development Program of China (2018YFC0604705), Fundamental Research Fund for the Central Universities (China University of Mining \& Technology, Grant 2013QNA16), National Natural Science Foundation of China (Grant 51974302).

Conflicts of Interest: The authors declare no competing financial interest.

\section{References}

1. Long, C.; Xiao, Y.; Zheng, M.T.; Hu, H.; Dong, H.W.; Lei, B.F.; Zhang, H.R.; Zhuang, J.L.; Liu, Y.L. Synthesis of hybrid Ni-Co oxide @ 3D carbon skeleton derived from pollen grains for advanced supercapacitors. Electrochim. Acta 2016, 210, 695-703. [CrossRef]

2. Geuli, O.; Hao, Q.L.; Mandler, D. One-step fabrication of NiOx-decorated carbon nanotubes- $\mathrm{NiCo}_{2} \mathrm{O}_{4}$ as an advanced electroactive composite for supercapacitors. Electrochim. Acta 2019, 318, 51-60. [CrossRef]

3. Hao, L.; Li, X.L.; Zhi, L.J. Carbonaceous electrode materials for supercapacitors. Adv. Mater. 2013, 25, 3899-3904. [CrossRef] [PubMed]

4. Zhang, L.; Li, T.H.; Ji, X.G.; Zhang, Z.Y.; Yang, W.B.; Gao, J.J.; Li, H.; Xiong, C.Y.; Dang, A. Freestanding three-dimensional reduced graphene oxide/ $\mathrm{MnO}_{2}$ on porous carbon/nickel foam as a designed hierarchical multihole supercapacitor electrode. Electrochim. Acta 2017, 252, 306-314. [CrossRef]

5. Zhang, L.L.; Zhao, X.S. Carbon-based materials as supercapacitor electrodes. Chem. Soc. Rev. 2009, 38, 2520-2531. [CrossRef] [PubMed]

6. Liu, R.H.; Liu, E.H.; Ding, R.; Liu, K.; Teng, Y.; Luo, Z.Y.; Li, Z.P.; Hu, T.T.; Liu, T.T. Facile in-situ redox synthesis of hierarchical porous activated carbon@ $\mathrm{MnO}_{2}$ core/shell nanocomposite for supercapacitors. Ceram. Int. 2015, 41, 12734-12741. [CrossRef]

7. Wang, J.W.; Chen, Y.; Chen, B.Z. A Synthesis Method of $\mathrm{MnO}_{2}$ /Activated Carbon Composite for Electrochemical Supercapacitors. J. Electrochem. Soc. 2015, 162, A1654-A1661. [CrossRef]

8. Yin, L.H.; Chen, Y.; Li, D.; Zhao, X.Q.; Hou, B.; Cao, B.K. 3-Dimensional hierarchical porous activated carbon derived from coconut fibers with high-rate performance for symmetric supercapacitors. Mater. Design 2016, 111, 44-50. [CrossRef]

9. Geng, X.; Li, L.X.; Li, F. Carbon nanotubes/activated carbon hybrid with ultrahigh surface area for electrochemical capacitors. Electrochim. Acta 2015, 168, 25-31. [CrossRef]

10. Jin, Z.; Yan, X.D.; Yu, Y.H.; Zhao, G.J. Sustainable activated carbon fibers from liquefied wood with controllable porosity for high-performance supercapacitors. J. Mater. Chem. A 2014, 2, 11706-11715. [CrossRef]

11. Qin, K.; Kang, J.; Li, J.; Shi, C.; Li, Y.; Qiao, Z.; Zhao, N. Free-standing porous carbon nanofiber/ultrathin graphite hybrid for flexible solid-state supercapacitors. ACS Nano 2015, 9, 481-487. [CrossRef] [PubMed] 
12. Bai, C.H.; Sun, S.G.; Xu, Y.Q.; Yu, R.J.; Li, H.J. Facile one-step synthesis of nanocomposite based on carbon nanotubes and Nickel-Aluminum layered double hydroxides with high cycling stability for supercapacitors. J. Colloid Interf. Sci. 2016, 480, 57-62. [CrossRef] [PubMed]

13. Liu, W.; Tang, Y.K.; Sun, Z.P.; Gao, S.S.; Ma, J.H.; Liu, L. A simple approach of constructing sulfur-containing porous carbon nanotubes for high-performance supercapacitors. Carbon. 2017, 115, 754-762. [CrossRef]

14. Ling, Z.; Wang, Z.Y.; Zhang, M.D.; Yu, C.; Wang, G.; Dong, Y.F.; Liu, S.H.; Wang, Y.W.; Qiu, J.S. Sustainable Synthesis and Assembly of Biomass-Derived B/N Co-Doped Carbon Nanosheets with Ultrahigh Aspect Ratio for High-Performance Supercapacitors. Adv. Funct. Mater. 2016, 26, 111-119. [CrossRef]

15. Chen, C.; Yu, D.F.; Zhao, G.Y.; Du, B.S.; Tang, W.; Sun, L.; Sun, Y.; Besenbacher, F.; Yu, M. Three-dimensional scaffolding framework of porous carbon nanosheets derived from plant wastes for high-performance supercapacitors. Nano Energy 2016, 27, 377-389. [CrossRef]

16. Pan, Z.H.; Zhi, H.Z.; Qiu, Y.C.; Yang, J.; Xing, L.D.; Zhang, Q.C.; Ding, X.Y.; Wang, X.S.; Xu, G.G.; Yuan, H. Achieving commercial-level mass loading in ternary-doped holey graphene hydrogel electrodes for ultrahigh energy density supercapacitors. Nano Energy 2018, 46, 266-276. [CrossRef]

17. Shao, Y.; Elkady, M.F.; Wang, L.J.; Zhang, Q.; Li, Y.; Wang, H.; Mousavi, M.F.; Kaner, R.B. Graphene-based materials for flexible supercapacitors. Chem. Soc. Rev. 2015, 44, 3639-3665. [CrossRef]

18. Abdelhamid, A.A.; Yang, X.; Yang, J.; Chen, X.; Ying, J.Y. Graphene-wrapped nickel sulfide nanoprisms with improved performance for Li-ion battery anodes and supercapacitors. Nano Energy 2016, 26, 425-437. [CrossRef]

19. Xing, B.L.; Guo, H.; Chen, L.J.; Chen, Z.F.; Zhang, C.X.; Huang, G.X.; Xie, W.; Yu, J.L. Lignite-derived high surface area mesoporous activated carbons for electrochemical capacitors. Fuel Process. Technol. 2015, 138, 734-742. [CrossRef]

20. Dong, S.A.; Ji, X.Y.; Yu, M.X.; Xie, Y.Y.; Zhang, D.W.; He, X.J. Direct synthesis of interconnected porous carbon nanosheet/nickel foam composite for high-performance supercapacitors by microwave-assisted heating. J. Porous Mater. 2018, 25, 923-933. [CrossRef]

21. Qin, B.; Wang, Q.; Zhang, X.H.; Xie, X.L.; Jin, L.; Cao, Q. One-pot synthesis of interconnected porous carbon derived from coal tar pitch and cellulose for high-performance supercapacitors. Electrochim. Acta 2018, 283, 655-663. [CrossRef]

22. Wang, L.X.; Wang, R.R.; Zhao, H.Y.; Liu, L.; Jia, D.Z. High rate performance porous carbon prepared from coal for supercapacitors. Mater. Lett. 2015, 149, 85-88. [CrossRef]

23. Abudu, P.; Wang, L.X.; Xu, M.J.; Jia, D.Z.; Wang, X.C.; Jia, L.X. Hierarchical porous carbon materials derived from petroleum pitch for high-performance supercapacitors. Chem. Phy. Lett. 2018, 702, 1-7. [CrossRef]

24. Xie, X.Y.; Dong, S.A.; Xiao, N.; Qiu, J.S.; He, X.J.; Shao, X.L. Synthesis of layered microporous carbons from coal tar by directing, space-confinement and self-sacrificed template strategy for supercapacitors. Electrochim. Acta 2017, 246, 634-642. [CrossRef]

25. Zhang, W.L.; Zhao, M.Z.; Liu, R.Y.; Wang, X.F.; Lin, H.B. Hierarchical porous carbon derived from lignin for high performance supercapacitor. Colloid. Surface A 2015, 484, 518-527. [CrossRef]

26. Xing, B.L.; Huang, G.X.; Chen, Z.F.; Chen, L.J.; Yi, G.Y.; Zhang, C.X. Facile preparation of hierarchical porous carbons for supercapacitors by direct carbonization of potassium humate. J. Solid State Electro. 2017, 21, 263-271. [CrossRef]

27. Xu, L.S.; Jia, M.Y.; Li, Y.; Jin, X.J.; Zhang, F. High-performance $\mathrm{MnO}_{2}$-deposited graphene/activated carbon film electrodes for flexible solid-state supercapacitor. Sci. Rep.-UK 2017, 7, 12857. [CrossRef]

28. Choi, P.R.; Kim, S.G.; Jung, J.C.; Kim, M.S. High-energy-density activated carbon electrode for organic electric-double-layer-capacitor using carbonized petroleum pitch. Carbon Lett. 2017, 22, 70-80.

29. Yin, J.; Zhang, D.Y.; Zhao, J.Q.; Wang, X.L.; Zhu, H.; Wang, C.Y. Meso- and micro-porous composite carbons derived from humic acid for supercapacitors. Electrochim. Acta 2014, 136, 504-512. [CrossRef]

30. Shang, S.M.; Yang, X.M.; Tao, X.M. Easy synthesis of carbon nanotubes with polypyrrole nanotubes as the carbon precursor. Polymer 2009, 50, 2815-2818. [CrossRef]

31. Chen, Y.Y.; Dhaiveegan, P.; Michalska, M.; Lin, J.Y. Morphology-controlled synthesis of nanosphere-like $\mathrm{NiCo}_{2} \mathrm{~S}_{4}$ as cathode materials for high-rate asymmetric supercapacitors. Electrochim. Acta 2018, 274, $208-216$. [CrossRef] 
32. Chen, H.Y.; Ai, Y.N.; Liu, F.; Chang, X.; Xue, Y.; Huang, Q.; Wang, C.; Lin, H.L.; Han, S. Carbon-coated Hierarchical Ni-Mn Layered Double Hydroxide Nanoarrays on Ni Foam for Flexible High-capacitance Supercapacitors. Electrochim. Acta 2016, 213, 55-65. [CrossRef]

33. Zhang, X.M.; Ma, J.; Yang, W.L.; Gao, Z.; Wang, J.; Liu, Q.; Liu, J.Y.; Jing, X.Y. Manganese dioxide core-shell nanowires in situ grown on carbon spheres for supercapacitor application. CrystEngComm 2014, 16, 4016-4022. [CrossRef]

34. Hao, X.Q.; Jiang, Z.Q.; Tian, X.N.; Hao, X.G.; Jiang, Z.J.; Hao, X.Q.; Jiang, Z.Q.; Tian, X.N.; Hao, X.G.; Jiang, Z.J. Facile Assembly of Co-Ni Layered Double Hydroxide Nanoflakes on Carbon Nitride Coated N-doped Graphene Hollow Spheres with High Electrochemical Capacitive Performance. Electrochim. Acta 2017, 253, 21-30. [CrossRef]

35. Pham, V.H.; Dickerson, J.H. Reduced Graphene Oxide Hydrogels Deposited in Nickel Foam for Supercapacitor Applications: Toward High Volumetric Capacitance. J. Phy. Chem. C 2016, 120, 5353-5360. [CrossRef]

36. He, X.J.; Zhang, N.; Shao, X.L.; Wu, M.B.; Yu, M.X.; Qiu, J.H. A layered- template-nanospace-confinement strategy for production of corrugated graphene nanosheets from petroleum pitch for supercapacitors. Chem. Eng. J. 2016, 297, 121-127. [CrossRef]

37. Li, J.; Liu, K.; Gao, X.; Yao, B.; Huo, K.; Cheng, Y.; Cheng, X.; Chen, D.; Wang, B.; Ding, D. Oxygen and nitrogen enriched 3D porous carbon for supercapacitors of high volumetric capacity. ACS Appl. Mater. Inter. 2015, 7, 24622-24628. [CrossRef]

38. Chmiola, J.; Yushin, G.; Gogotsi, Y.; Portet, C.; Simon, P.; Taberna, P.L. Anomalous increase in carbon capacitance at pore sizes less than 1 nanometer. Science 2006, 313, 1760-1763. [CrossRef]

39. He, X.J.; Li, X.J.; Ma, H.; Han, J.F.; Zhang, H.; Yu, C.; Xiao, N.; Qiu, J.S. ZnO template strategy for the synthesis of $3 \mathrm{D}$ interconnected graphene nanocapsules from coal tar pitch as supercapacitor electrode materials. J. Power Sources 2017, 340, 183-191. [CrossRef]

40. Han, S.S.; Hou, F.; Yuan, X.B.; Liu, J.C.; Yan, X.; Chen, S.Q. Continuous hierarchical carbon nanotube/reduced graphene oxide hybrid films for supercapacitors. Electrochim. Acta 2017, 225, 566-573. [CrossRef]

41. Li, Z.; Xu, Z.W.; Wang, H.L.; Ding, J.; Zahiri, B.; Holt, C.M.B.; Tan, X.H.; Mitlin, D. Colossal pseudocapacitance in a high functionality-high surface area carbon anode doubles the energy of an asymmetric supercapacitor. Energ. Environ. Sci. 2014, 7, 1708-1718. [CrossRef]

42. Zhang, Z.Q.; Zhang, H.D.; Zhang, X.Y.; Yu, D.Y.; Ji, Y.; Sun, Q.S.; Wang, Y.; Liu, X.Y. Facile synthesis of hierarchical $\mathrm{CoMoO}_{4} @ \mathrm{NiMoO}_{4}$ core-shell nanosheet arrays on nickel foam as an advanced electrode for asymmetric supercapacitors. J. Mater. Chem. A 2016, 4, 18578-18584. [CrossRef]

43. Li, Y.; Xu, Z.Y.; Wang, D.W.; Zhao, J.; Zhang, H.H. Snowflake-like core-shell $\alpha-\mathrm{MnO}_{2} @ \delta-\mathrm{MnO}_{2}$ for high performance asymmetric supercapacitor. Electrochim. Acta 2017, 251, 344-354. [CrossRef]

44. Yan, J.; Wang, Q.; Wei, T.; Fan, Z.J. Recent Advances in Design and Fabrication of Electrochemical Supercapacitors with High Energy Densities. Adv. Energy Mater. 2014, 4, 157-164. [CrossRef]

45. Shao, J.Q.; Ma, F.W.; Wu, G.; Dai, C.C.; Geng, W.D.; Song, S.J.; Wan, J.F. In-situ MgO (CaCO $\left.{ }_{3}\right)$ templating coupled with $\mathrm{KOH}$ activation strategy for high yield preparation of various porous carbons as supercapacitor electrode materials. Chem. Eng. J. 2017, 321, 301-313. [CrossRef]

46. Das, T.; Chauhan, H.; Deka, S.; Chaudhary, S.; Boruah, R.; Saikia, B.K. Promising carbon nanosheet-based supercapacitor electrode materials from low-grade coals. Micropor. Mesopor. Mater. 2017, 253, 80-90. [CrossRef]

47. Shao, J.; Zhou, X.; Liu, Q.; Zou, R.; Li, W.; Yang, J.; Hu, J. Mechanism analysis of the capacitance contributions and ultralong cycling-stability of the isomorphous $\mathrm{MnO}_{2} @ \mathrm{MnO}_{2}$ core/shell nanostructures for supercapacitors. J. Mater. Chem. A 2015, 3, 6168-6176. [CrossRef]

48. Li, S.F.; Yu, C.; Yang, J.; Zhao, C.T.; Fan, X.M.; Huang, H.W.; Han, X.T.; Wang, J.X.; He, X.J.; Qiu, J.H. Ultrathin Nitrogen-Enriched Hybrid Carbon Nanosheets for Supercapacitors with Ultrahigh Rate Performance and High Energy Density. Chemelectrochem. 2017, 4, 369-375. [CrossRef]

49. Xu, K.B.; Li, W.Y.; Liu, Q.; Li, B.; Liu, X.J.; An, L.; Chen, Z.Q.; Zou, R.J.; Hu, J.Q. Hierarchical mesoporous $\mathrm{NiCoO} @ \mathrm{MnO}$ core-shell nanowire arrays on nickel foam for aqueous asymmetric supercapacitors. J. Mater. Chem. A 2014, 2, 4795-4802. [CrossRef]

50. Zhang, J.L.; Zhang, W.F.; Han, M.F.; Pang, J.; Xiang, Y.; Cao, G.P.; Yang, Y.S. Synthesis of nitrogen-doped polymeric resin-derived porous carbon for high performance supercapacitors. Micropor. Mesopor. Mater. 2018, 270, 204-210. [CrossRef] 
51. Xu, J.; Li, J.Q.; Yang, Q.L.; Xiong, Y.; Chen, C.G. In-situ Synthesis of $\mathrm{MnO}_{2}$ @Graphdiyne Oxides Nanocomposite with Enhanced Performance of Supercapacitors. Electrochim. Acta 2017, 251, 672-680. [CrossRef]

52. Zhang, D.Y.; Zhang, Y.H.; Luo, Y.S.; Chu, P.K. Highly porous honeycomb manganese oxide@carbon fibers core-shell nanocables for flexible supercapacitors. Nano Energy 2015, 13, 47-57. [CrossRef]

53. Hao, J.N.; Liao, Y.Q.; Zhong, Y.Y.; Shu, D.; He, C.; Guo, S.T.; Huang, Y.L.; Zhong, J.; Hu, L.L. Three-dimensional graphene layers prepared by a gas-foaming method for supercapacitor applications. Carbon 2015, 94, 879-887. [CrossRef]

Sample Availability: Samples of the compounds are available from the authors.

(C) 2019 by the authors. Licensee MDPI, Basel, Switzerland. This article is an open access article distributed under the terms and conditions of the Creative Commons Attribution (CC BY) license (http://creativecommons.org/licenses/by/4.0/). 